\title{
Tunable Synthesis of Nitrogen Doped Graphene from Fluorographene under Mild Conditions
}

Dagmar Zaoralová, Vítězslav Hrubý,\$ Veronika Šedajová, Radim Mach, Vojtěch Kupka, Juri Ugolotti, Aristides Bakandritsos, * Miroslav Medved',* and Michal Otyepka*

Cite This: ACS Sustainable Chem. Eng. 2020, 8, 4764-4772

Read Online

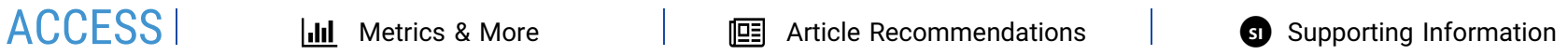

ABSTRACT: The nitrogen doping of graphene via mild and low energy processes to afford homogeneous product composition and topology with high nitrogen content (>10 at. \%) remains a challenge of contemporary $2 \mathrm{D}$ materials chemistry. Here, we report a previously unexplored route to synthesize $\mathrm{N}$-doped graphene (NG) with exceptionally high $\mathrm{N}$ content (up to 18.2 at. \%) by reaction of fluorographene (FG) with $\mathrm{NaNH}_{2}$ in $\mathrm{N}, \mathrm{N}$-dimethylformamide (at $130{ }^{\circ} \mathrm{C}$ ) or acetonitrile (at $70{ }^{\circ} \mathrm{C}$ ). The $\mathrm{N}$ content can be tuned by changing the reaction time, temperature, and/or solvent, ranging from 6.6 to 18.2 at. \%, mainly in the form of pyridinic and pyrrolic configurations. With thermal annealing, the $\mathrm{N}$ content remained constant up to $400{ }^{\circ} \mathrm{C}$ but then decreased by $\sim 50 \%$ upon being further annealed to $1000{ }^{\circ} \mathrm{C}$. Density functional

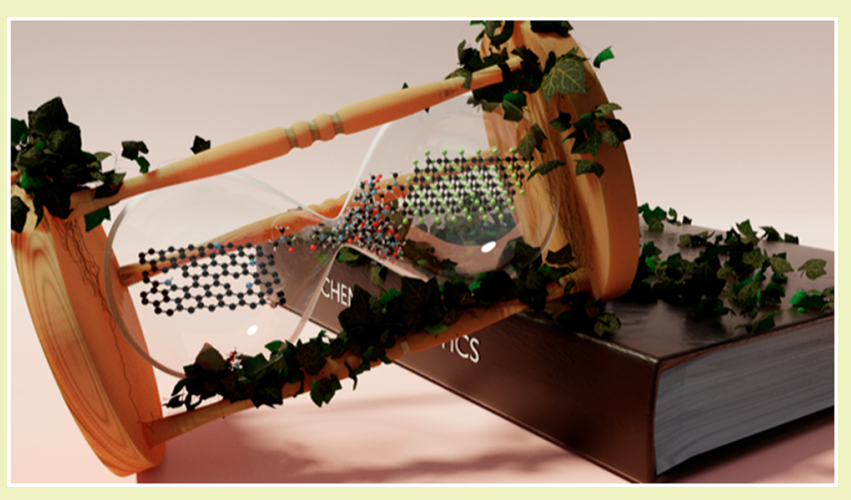
theory (DFT) calculations showed that nitrogen incorporation into the carbon lattice mostly occurred at vacancies present in the starting material. We also conducted a thorough rationalization of sidereaction pathways leading to byproducts, which were confirmed by GC-MS analysis. This is the highest yet recorded $\mathrm{N}$ content for a wet chemical doping procedure and at such a low temperature of $70{ }^{\circ} \mathrm{C}$. The reported synthetic approach thus offers a sustainable and cost-effective way to prepare NG with a broad tunability window of $\mathrm{N}$ content for potential applications related to energy storage and catalysis.

KEYWORDS: Nitrogen-doped graphene, Fluorographene, Wet chemistry, Eco-friendly organic synthesis, Density functional theory, Reaction mechanism

\section{INTRODUCTION}

Doping graphene with heteroatoms can significantly alter its electronic structure, giving rise to novel $2 \mathrm{D}$ materials with tunable electronic, magnetic, and chemical properties that can be exploited in diverse applications. ${ }^{1,2}$ In particular, nitrogen doping can imprint active centers on graphene suitable for (electro) catalytic, ${ }^{3-7}$ electrochemical (energy storage and sensors), ${ }^{3}$ and spintronic applications. ${ }^{8-12}$ Currently, methods for preparing nitrogen-doped graphene (NG) mostly rely on chemical vapor deposition of nitrogen-containing molecules, ${ }^{13,14}$ high temperature $\mathrm{NH}_{3}$ treatment of $\mathrm{GO}^{15}$ and graphene, ${ }^{5}$ or solvothermal reaction of GO with $\mathrm{N}$-containing molecules (e.g., melamine, acetonitrile, pyridine, urea, hydrazine) with subsequent annealing at high temperatures. ${ }^{16,17}$ Comprehensive reviews of synthetic pathways for NG can be found in pertinent articles. ${ }^{1,3,6,18}$ Although high Ncontent NGs (ca. 7 at. \%) can be obtained through solvothermal pathways and annealing, ${ }_{5,11}^{16,17}$ or high temperature treatment of oxidized graphenes, ${ }^{5,15,19}$ such pathways are energy-demanding due to the high temperatures required (usually $\geq 800{ }^{\circ} \mathrm{C}$ ). In addition, solid state reactions often lead to an inhomogeneous distribution of nitrogen in the lattice. $^{20,21}$

Interestingly, fluorographene (FG) has been reported to undergo $\mathrm{N}$-doping after Hummers oxidation to form fluorographene oxide, which after heating at $800{ }^{\circ} \mathrm{C}$ with melamine affords NG with $\mathrm{N}$ levels of 2 at. \%. ${ }^{4}$ However, although a structurally well-defined graphene derivative ${ }^{22}$ was used as a substrate, allowing homogeneous doping, the pathway relied on established high temperature routes and yielded only low $\mathrm{N}$ content. It was also demonstrated that FG can undergo direct $\mathrm{N}$-doping by ammonia gas which occurs simultaneously with defluorination at temperatures between 200 and $400{ }^{\circ} \mathrm{C} .{ }^{23,24}$ Density functional theory (DFT) calculations have revealed that the first reaction step involves nucleophilic substitution of fluorine atoms by amino groups,

Received: November 30, 2019

Revised: February 2, 2020

Published: February 25, 2020 

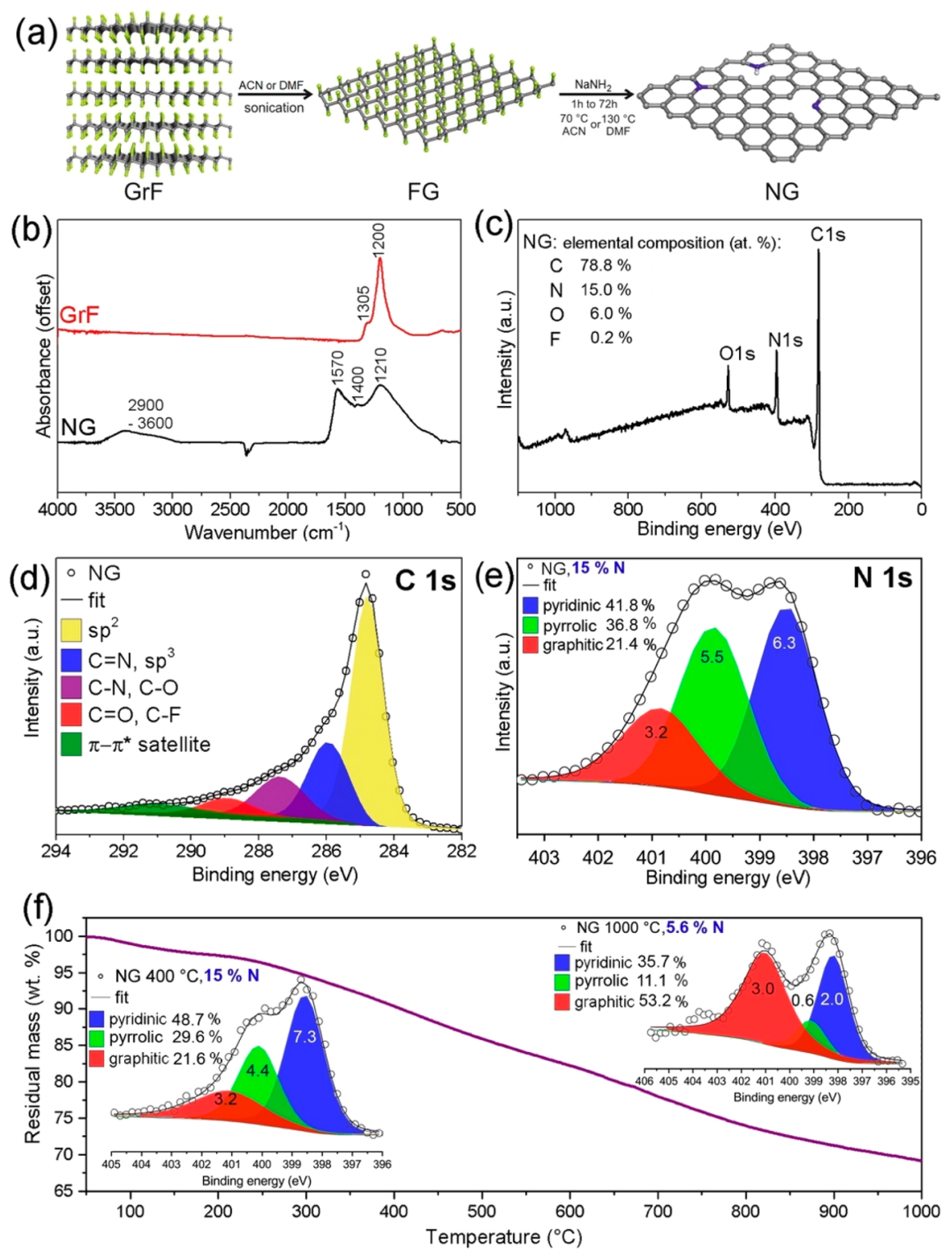

Figure 1. (a) General synthetic route toward NG. (b) FT-IR spectra of starting material (GrF) and product (NG). (c) XPS survey spectrum of NG synthesized at $130{ }^{\circ} \mathrm{C}$ in DMF. (d) Deconvoluted C 1s, and (e) N 1s XPS envelopes (the numbers in the legends represent the atomic contents of different $\mathrm{N}$ configurations with respect to nitrogen atoms only; the numbers inside the curves represent the atomic contents of different $\mathrm{N}$ configurations with respect to all atoms in the material). (f) TGA of NG in $\mathrm{N}_{2}$ (insets show deconvoluted $\mathrm{N}$ 1s envelopes of NG samples withdrawn at 400 and $1000{ }^{\circ} \mathrm{C}$ ).

which can then undergo deprotonation and cyclization into aziridinic configurations. These could potentially be transformed into either pyridinic or graphitic $\mathrm{N}$ in the honeycomb carbon lattice. Owing to formation of $\mathrm{NH}_{4} \mathrm{~F}$ during the solid state synthesis (with characteristic double IR band of $\left[\mathrm{NH}_{4}\right]^{+}$ at ca. $3250 \mathrm{~cm}^{-1}$ present at $300-400{ }^{\circ} \mathrm{C}$, along with some XRD peaks), the nitrogen content might not solely be attributed to doping. Despite these interesting results, the methods still rely on rather high temperatures $\left(300-500{ }^{\circ} \mathrm{C}\right.$ ) and usage of toxic, flammable, and environmentally dangerous ammonia gas. Recently, we reported the synthesis of $\mathrm{NG}^{25}$ with 8.6 at. \% $\mathrm{N}$ content (or 9.8 N/C at. ratio) homogeneously distributed in the graphene lattice by exploiting the expanding wet chemistry of $\mathrm{FG}^{26}$ In particular, $\mathrm{FG}$ reacted with $\mathrm{NH}_{2} \mathrm{OH}$. $\mathrm{HCl}$ in $\mathrm{DMF}$ at $130{ }^{\circ} \mathrm{C}$ for $30 \mathrm{~h}$. The $\mathrm{N}$-doping was explained to have begun with decomposition of $\mathrm{NH}_{2} \mathrm{OH}$ into ammonia, which then reacted with vacancies present in the FG lattice, incorporating mostly pyridinic $\mathrm{N}$ atoms. Nevertheless, $\mathrm{NH}_{2} \mathrm{OH} \cdot \mathrm{HCl}$ is acutely toxic ${ }^{27}$ and the achieved $\mathrm{N}$-content remained at similar levels as previously reported. Therefore, the development of a simple, cost-effective, and eco-friendly synthetic pathway that gives access to homogeneous $\mathrm{N}$-doping with elevated $\mathrm{N}$ content continues to be an experimental challenge. Moreover, the achievement of high levels of $\mathrm{N}$ doping would be beneficial for a wide range of NG materials applications, such as in (electro)catalysis for energy production and materials for energy storage.

In the present work, we showed that wet chemistry of FG, even at mild temperatures as low as $70{ }^{\circ} \mathrm{C}$, afforded up to 18.2 at. \% $\mathrm{N}$-doping when the more reactive and less healthhazardous ${ }^{28} \mathrm{NaNH}_{2}$ was used (Figure 1a). Interestingly, the $\mathrm{N}$-doping was tunable by the tweaking of the reaction conditions, such as time, temperature, and solvent environment. In particular, the reaction proceeded in DMF (r.t.-130 


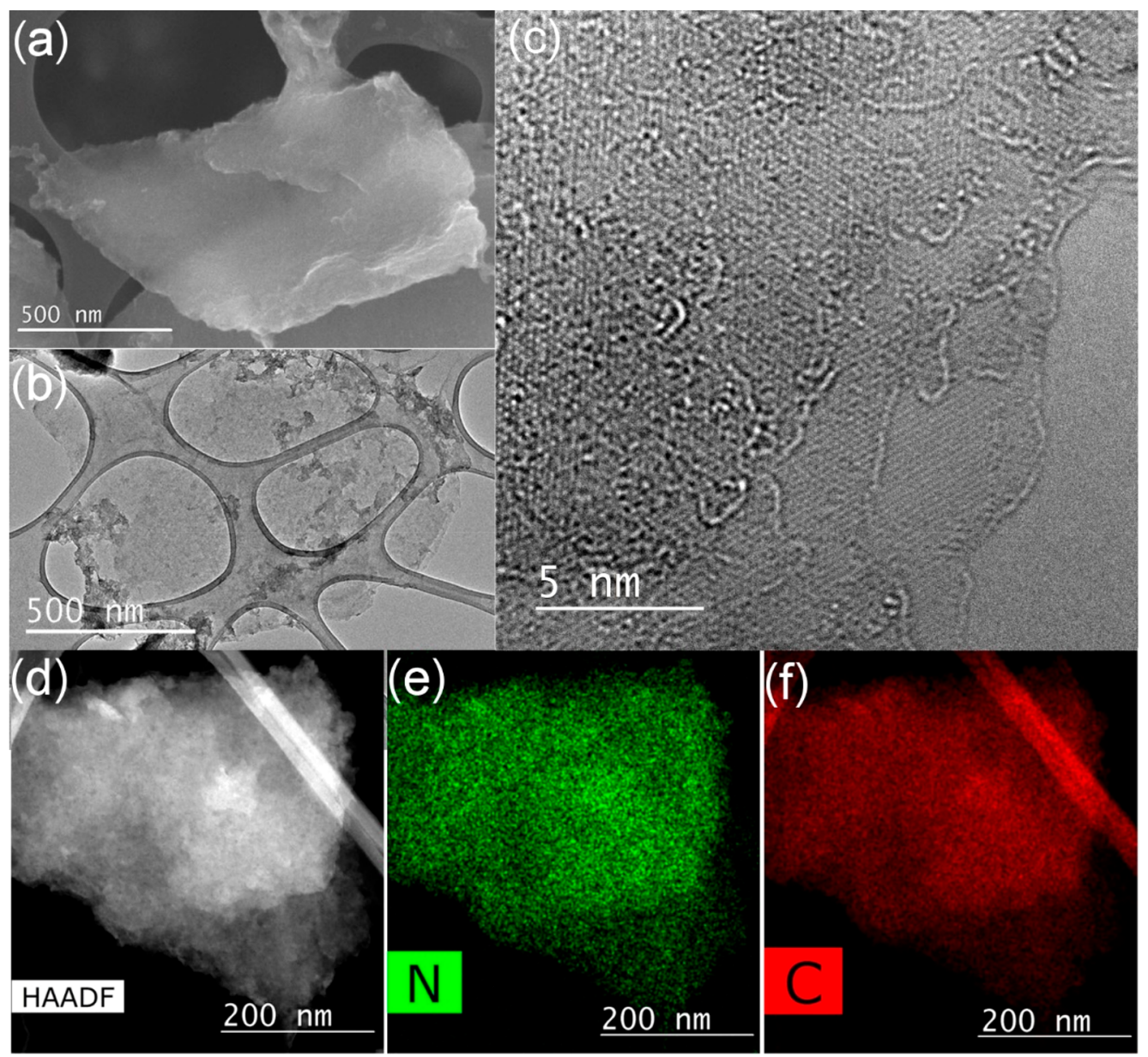

Figure 2. (a) SEM and (b) HR-TEM images of a few-layered NG flake. (c) Magnification of the same flake showing its edge structure and the atomic lattice of the graphene skeleton. (d) High angle annular dark-field (HAADF) TEM image of the flake used for energy-dispersive X-ray spectroscopy chemical mapping (EDS) for (e) nitrogen and (f) carbon.

$\left.{ }^{\circ} \mathrm{C}\right)$, acetonitrile $\left(\mathrm{ACN}, 70{ }^{\circ} \mathrm{C}\right)$, and propylene carbonate $(\mathrm{PC}$, $130{ }^{\circ} \mathrm{C}$ ) as solvents. The solvent DMF is relatively environmentally friendly as it is rapidly biodegradable when released to water and soil (with a half-life of 18-36 h) and photooxidizable in air over a period of days. ${ }^{29}$ With acetonitrile, we obtained not only a more environmentally friendly process but also one that was safer to human health than that with $\mathrm{DMF},{ }^{30-32}$ combined with homogeneous and record $\mathrm{N}$-doping levels (18.2 at. \%). To elucidate the high-yield incorporation of $\mathrm{N}$ atoms into the graphene lattice, we employed DFT calculations. Vacancies in FG were shown to act as reactive centers for $\left[\mathrm{NH}_{2}\right]^{-}$nucleophilic attack, followed by healing or expansion of the vacancies, whereas direct $\mathrm{N}$ incorporation into the unperturbed FG lattice was found to be energetically demanding.

\section{RESULTS AND DISCUSSION}

Synthesis and Characterization of Nitrogen-Doped Graphene. NG was synthesized using graphite fluoride ( $\mathrm{GrF})$ as a starting material, which was first exfoliated by sonication in solvent into several-layered sheets of FG and then reacted with sodium amide $\left(\mathrm{NaNH}_{2}\right)$ at $130{ }^{\circ} \mathrm{C}(\mathrm{DMF})$ or $70{ }^{\circ} \mathrm{C}(\mathrm{ACN})$ for a maximum of 3 days (Figure 1a). The FT-IR spectrum of the starting GrF (Figure 1b) showed only bands from the CF and $\mathrm{CF}_{2}$ bonds (1200 and $1305 \mathrm{~cm}^{-1}$, respectively), whereas the spectrum of the NG derivative in DMF was dominated by bands at 1570 and $1210 \mathrm{~cm}^{-1}$ due to the developed $\mathrm{sp}^{2}$ carbon network. Both the latter vibrations are typical for carbon and heterocyclic aromatic rings. ${ }^{33}$ Additional vibrational modes of the aromatic rings appearing at $1400 \mathrm{~cm}^{-1}$ were ascribed to heteroatom substitution (such as in pyridinic configurations). ${ }^{33,34}$ Theoretical IR calculations were also in agreement with the present interpretation. ${ }^{35,36}$ The $1210 \mathrm{~cm}^{-1}$ band in NG overlapped with that of CF vibrations, but XPS confirmed (Figure 1c) that almost all $\mathrm{F}$ atoms (0.2 at. \% residue) were eliminated. A weak and broad feature in the region between 3600 and $2900 \mathrm{~cm}^{-1}$ may indicate the minor presence of $\mathrm{N}-$ $\mathrm{H}, \mathrm{C}-\mathrm{H}$, and $\mathrm{O}-\mathrm{H}$ groups. The Raman spectrum of NG consisted of two features at 1300 and $1590 \mathrm{~cm}^{-1}$, corresponding to D and G bands, respectively (Figure S2). The broad character of the D-band and high $I_{\mathrm{D}} / I_{\mathrm{G}}$ ratio value of 1.3 suggested the presence of a large number of point defects and/or highly functionalized graphene materials, whereas the G-band was assigned to vibrations of $\mathrm{sp}^{2}$ carbon domains formed by the reductive defluorination of $\mathrm{FG} .^{8}$ As discussed later, the NG products obtained from reaction at shorter times ( 1 to $24 \mathrm{~h}$ ) or in ACN exhibited very similar features.

According to XPS analysis, the product was doped with exceptionally high $\mathrm{N}$ content of 15 at. \% in DMF (Figure 1c) and 18.2 at. $\%$ in $\mathrm{ACN}$ (Figure 3c), and was practically fluorine-free (F: $0.2-0.9$ at. \%). In comparison to the material 

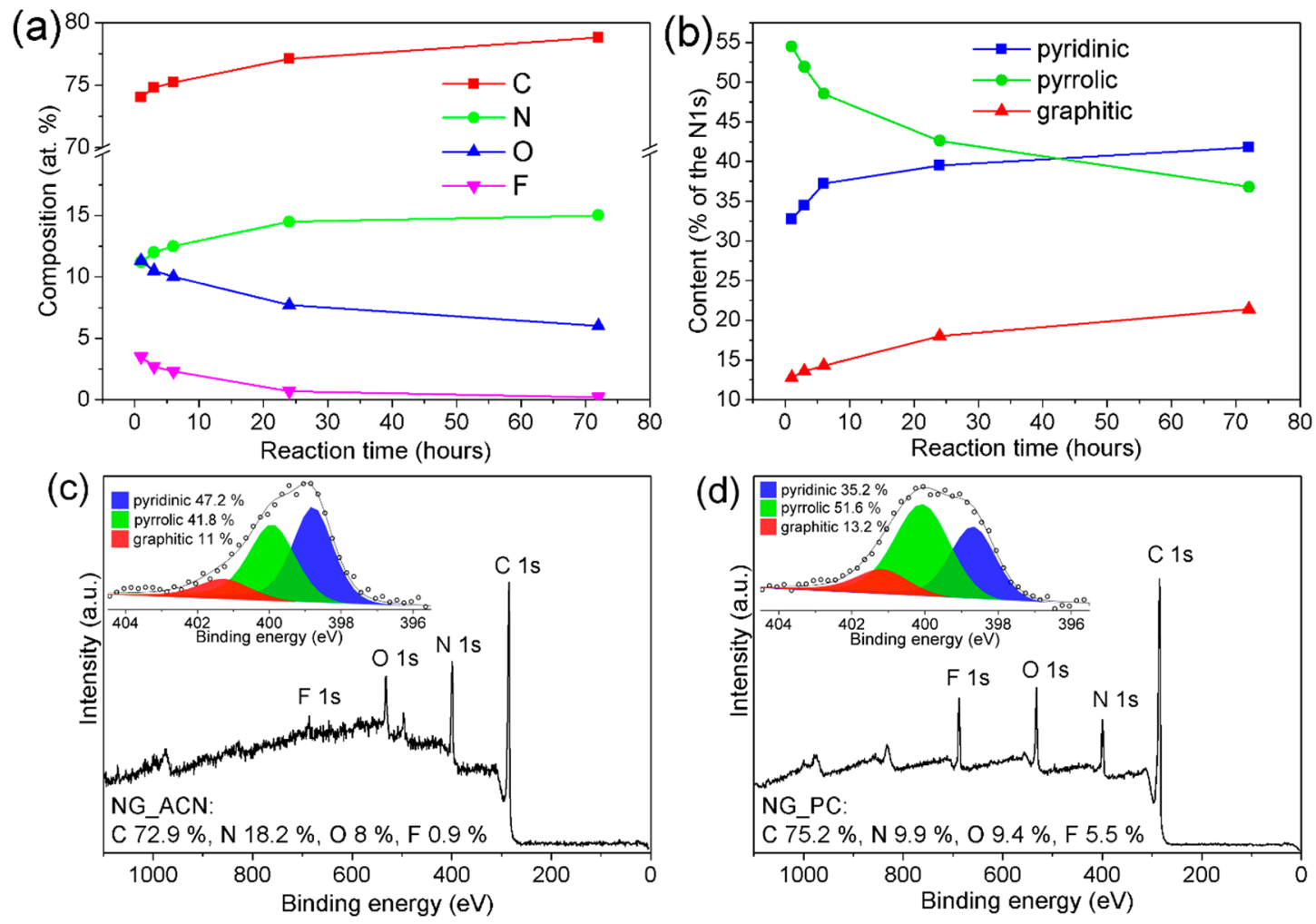

Figure 3. (a) Time evolution of the elemental composition of NG materials synthesized at $130{ }^{\circ} \mathrm{C}$. (b) Time evolution of nitrogen group components acquired by deconvolution of N 1s XPS regions of NG materials synthesized at $130{ }^{\circ} \mathrm{C}$. (c) Survey XPS spectrum of NG_ACN material prepared at $70^{\circ} \mathrm{C}$ with its deconvoluted $\mathrm{N}$ 1s region (inset). (d) Survey XPS spectrum of NG_PC with its deconvoluted N 1s region (inset).

reported by Zoppellaro et al. ${ }^{25}$ (F: 7.7 at. \% and N: 8.2 at. \%), the reaction with $\mathrm{NaNH}_{2}$ achieved a much higher degree of defluorination and significantly higher (almost twice) nitrogen doping level. Indeed, deconvolution of the high-resolution $\mathrm{C}$ 1s XPS (HR-XPS) profile (Figure 1d) showed that the NGs consisted mostly of $\mathrm{sp}^{2}$-hybridized carbons and other components at higher binding energies (BEs), corresponding to carbons bonded to nitrogen and oxygen atoms with significantly overlapping binding energy values. ${ }^{3,8,25,37,38}$ The HR-XPS $N$ 1s profile suggested the presence of three components (Figure 1e) with BEs of 398.5, 400, and $\sim 401.2 \mathrm{eV}$, typically assigned to pyridinic, pyrrolic, and graphitic configurations, respectively..$^{3,8,25,36,38}$ After the thermal treatment of $\mathrm{NG}$ at $400{ }^{\circ} \mathrm{C}$ in an inert atmosphere (Figure 1f), the $\mathrm{N}$ content remained practically unchanged (15 at. \%, Figure S3). However, the deconvoluted $\mathrm{N} 1$ s envelopes (insets in Figure 1f) revealed that pyrrolic nitrogens were partly transformed to thermodynamically more stable pyridinic nitrogens. At $1000{ }^{\circ} \mathrm{C}$, the pyrrolic nitrogens were further reduced with a concomitant reduction of pyridinic nitrogen, while the content of graphitic nitrogen remained virtually the same, as expected for this configuration. It should be noted that in the $\mathrm{BE}$ range for pyrrolic nitrogens, other groups may also appear, such as amino and aziridinic groups. Nevertheless, presence of these groups is less probable in view of the high stability of this component up to $400{ }^{\circ} \mathrm{C}$, which would not be expected for such out-of-plane functionalities. Ninhydrin tests (Figure S4) also did not support the presence of amino groups. $^{39}$ The component ascribed to pyrrolic nitrogens probably contained a significant amount of protonated pyridinic nitrogens, as suggested by significant changes of the spectral areas at $\sim 398.5$ and $\sim 400 \mathrm{eV}$ in the N 1s XPS profiles of the NG material after acidic and basic washings ${ }^{36}$ (Figure S5). The dominant presence of pyridinic nitrogens was also supported by the 5.4 point of zero charge of the NG (Figure S6), which coincided with the $\mathrm{p} K_{\mathrm{a}}$ of pyridine $(5.2){ }^{36}$ However, for the sake of clarity, the component at $400 \mathrm{eV}$ is denoted throughout the text as pyrrolic.

SEM imaging revealed few-layered flakes or agglomerates with a lateral size of up to $1 \mu \mathrm{m}$ (Figure $2 \mathrm{a}$ ), in agreement with HR-TEM images showing almost transparent flakes of $c a .1 \mu \mathrm{m}$ (Figure 2b). Magnification of the edges confirmed a layered structure of stacked sheets with a distinguishable lattice in each layer (Figure 2c). Importantly, EDS chemical mapping revealed the homogeneous distribution of nitrogen atoms over the carbon lattice (Figure $2 \mathrm{~d}-\mathrm{f}$ ). The specific surface areas of the products as obtained by $\mathrm{N}_{2}$ and $\mathrm{CO}_{2}$ adsorption isotherms were 110 and $287 \mathrm{~m}^{2} / \mathrm{g}$, respectively (Figure S7a). The higher value from the $\mathrm{CO}_{2}$ measurement was attributed to its higher diffusion rate ensuring better accessibility in narrow pores; it thus probed constricted spaces more accurately than $\mathrm{N}_{2}$ at $77 \mathrm{~K}$. Adsorption of $\mathrm{CO}_{2}$ revealed micropore volume filling of around $0.025 \mathrm{~cm}^{3} / \mathrm{g}$ (Figure S7b); on the contrary, $\mathrm{N}_{2}$ did not show filling of the micropores. According to pore size distribution characteristics, the size of the micropores was around $0.4 \mathrm{~nm}$, i.e., in the range of ultramicropores $(<0.7 \mathrm{~nm})$.

To gain a deeper insight into the $\mathrm{N}$-doping process of $\mathrm{FG}$, samples were synthesized using different reaction times, temperatures, and solvents. The XPS spectra of the samples withdrawn at different times of the reaction performed at 130 ${ }^{\circ} \mathrm{C}$ suggested that the initial phase of the reaction was very fast. Within $1 \mathrm{~h}$, the fluorine content decreased from 52.3 at. \% 
Scheme 1. Possible Side-Reactions in FG Reacted with $\mathrm{NaNH}_{2}$ in $\mathrm{DMF}^{a}$

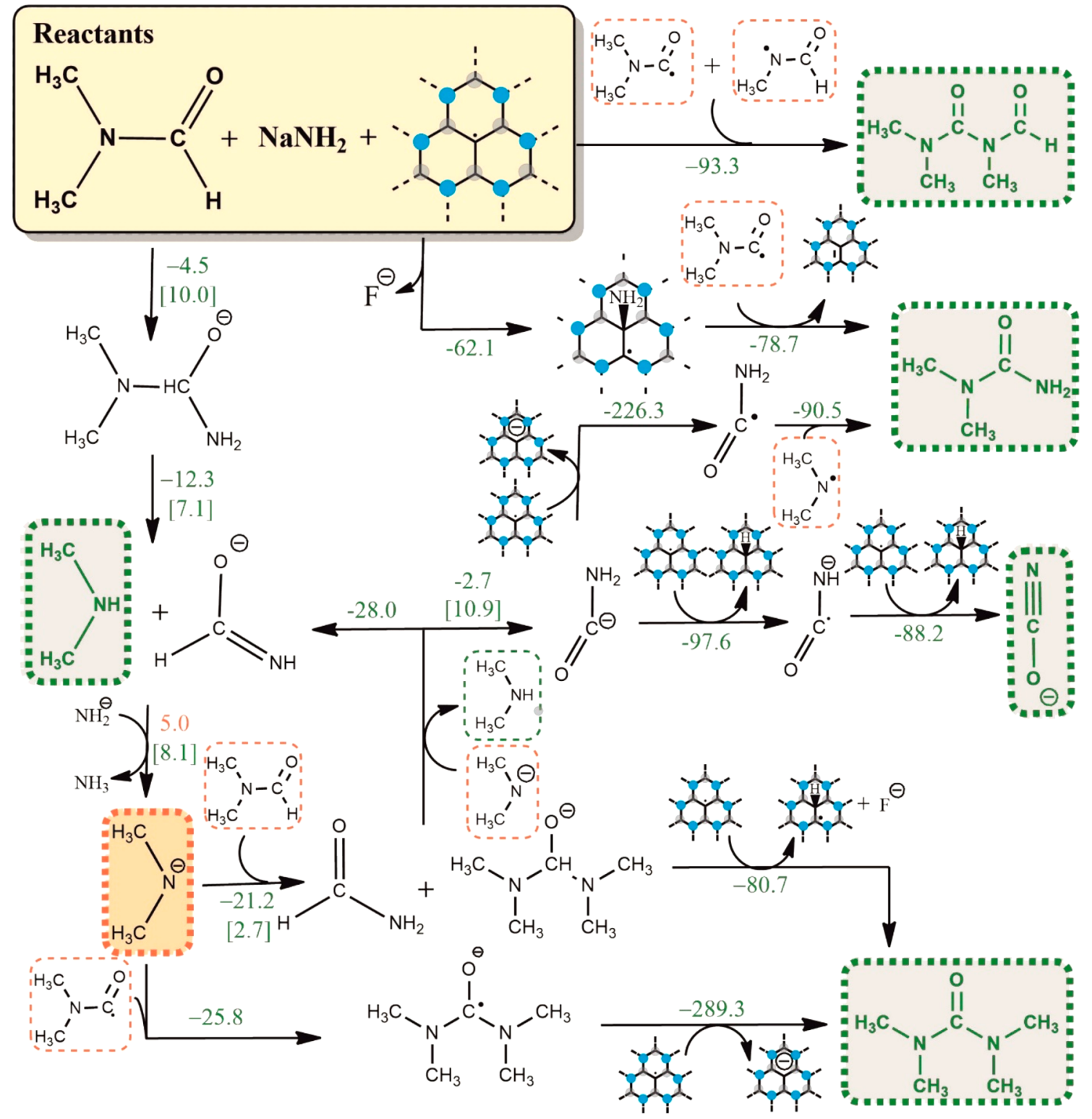

${ }^{a}$ Products in green frames were observed experimentally; products in orange frames play important roles in other reactions that take place in FG + $\mathrm{NaNH}_{2}+$ DMF system. Reaction energies and energy barriers (reported for endothermic and the least exothermic processes in brackets) were obtained at the $\omega \mathrm{B} 97 \mathrm{X}-\mathrm{D} / 6-31++\mathrm{G}(\mathrm{d}, \mathrm{p}) / \mathrm{SMD}$ level of theory. All values are in $\mathrm{kcal} \cdot \mathrm{mol}^{-1}$.

(Figure S8) to 3.5 at. \% (Figures 3a and S9), and the nitrogen content exceeded 11 at. \%. The N 1s XPS envelope at this point (1h, Figure S10a) revealed a much higher component at $\sim 400 \mathrm{eV}$ of 54.5 at. \% compared to that of the final product (Figure 1e, 36.8 at. \%). As the reaction proceeded beyond $1 \mathrm{~h}$, $\mathrm{F}$ atoms were further eliminated while $\mathrm{N}$ atoms were increased (Figure 3a) and the component at $\sim 400 \mathrm{eV}$ was partially transformed to that at $398.5 \mathrm{eV}$ (Figures $3 \mathrm{~b}$ and S10), indicating rearrangement of the less stable pyrrolic structures $^{25,40,41}$ to pyridinic configurations. Oxygen was introduced during the initial stage of the process but gradually decreased as the reaction continued (Figures $3 a$ and S9). FT-IR and Raman spectra showed the same features for all products as the sample which was treated for 3 days (Figure S11). Interestingly, the doping process was almost complete at 24 $h$, since the $\mathrm{N}$ and $\mathrm{F}$ contents reached 14.5 and $0.7 \%$, respectively, compared to 15 and $0.2 \%$ at $72 \mathrm{~h}$, suggesting the energy demands of the reaction could be reduced by using the shorter reaction time.

To investigate the possibility of $\mathrm{N}$-doping under mild and eco-friendly conditions, the reaction was also performed at 70 ${ }^{\circ} \mathrm{C}$ in DMF for $72 \mathrm{~h}$. The product was similar to that obtained after 3 to $6 \mathrm{~h}$ of reaction at $130{ }^{\circ} \mathrm{C}$ in terms of the elemental composition as well as nitrogen functionalities (Figure S12), indicating that the reaction still proceeded under such conditions, although at a rate decreased by an order of magnitude. Materials synthesized in acetonitrile (NG ACN) and propylene carbonate (NG_PC) at 70 and $1 \overline{3} 0{ }^{\circ} \mathrm{C}$, respectively, were also tested. NG ACN was practically fluorine-free (0.9 at. \%) and exhibited a remarkably high nitrogen content corresponding to 18.2 at. \% (Figure 3c). In similarity to the NG material, pyridinic groups amounted to almost half of the total nitrogen content of the NG_ACN material. NG_PC (Figure 3d) contained less nitrogen (9.9 at. 
(a) double vacancy

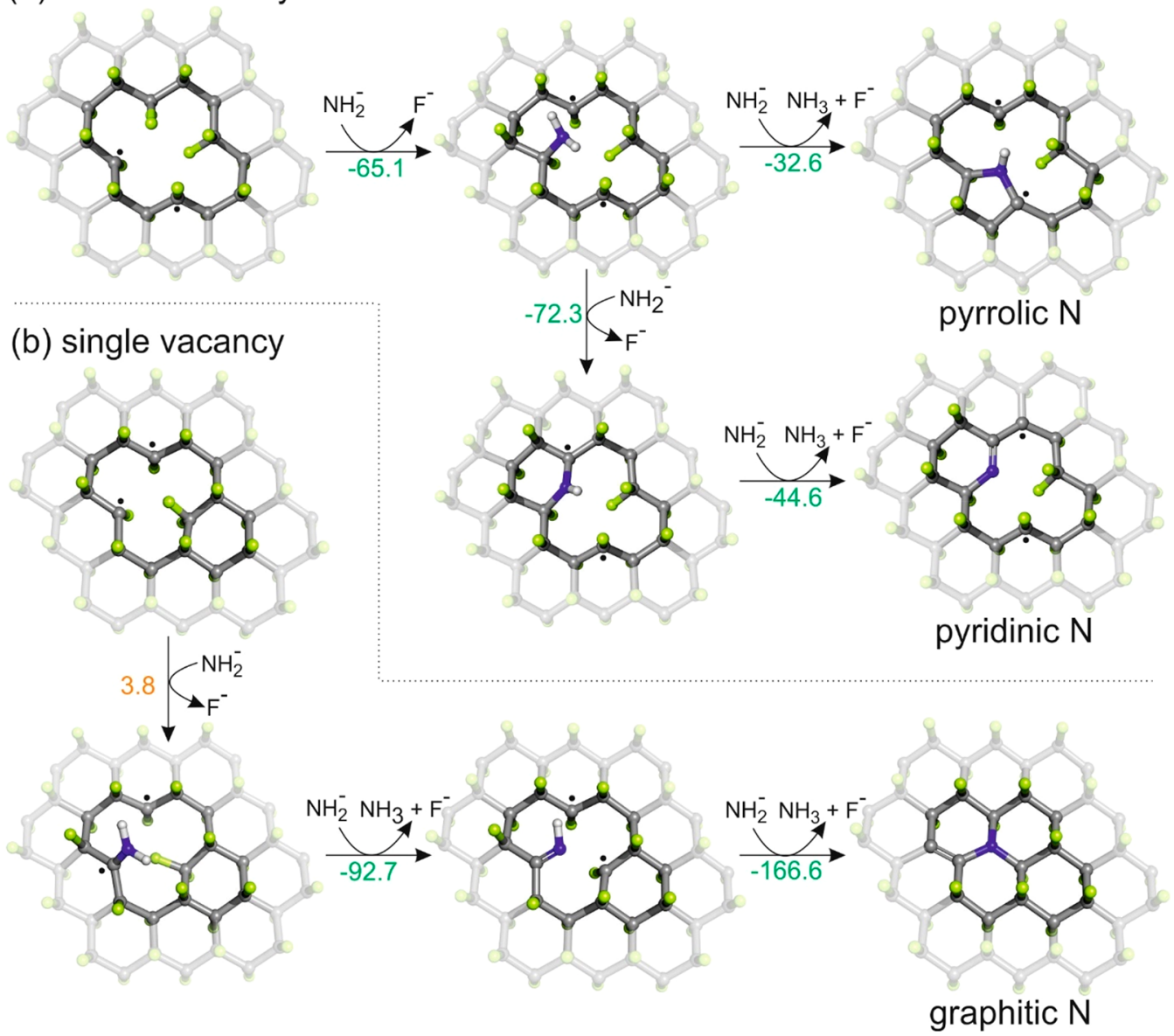

Figure 4. Nucleophilic attack of $\mathrm{NH}_{2}{ }^{-}$on a biradical center of (a) DV(14) leading to the formation pyrrolic or pyridinic nitrogen and (b) SV leading to the formation graphitic nitrogen. Carbon atoms are gray, fluorine green, nitrogen blue, and hydrogen white. Reaction energies are in kcal. $\mathrm{mol}^{-1}$.

$\%)$ with a lower proportion of pyridinic groups and more nitrogen atoms with BEs of around $400 \mathrm{eV}$. The possible reason for the higher $\mathrm{N}$ content in the case of $\mathrm{ACN}$ and $\mathrm{DMF}$ might be related to the fact that $\mathrm{NaNH}_{2}$ is notably less soluble in PC than in the other two solvents. Another possible reason could be the higher reactivity of carbonate esters (like PC) with strong nucleophiles (here, the $\mathrm{NH}_{2}{ }^{-}$anion), ${ }^{42}$ which can lead to more efficient competitive reactions compared to those in DMF and ACN.

Insights into the Reaction Mechanism. Various scenarios of nitrogen incorporation into the FG lattice were studied by DFT at the $\omega$ B97X-D/6-31++G $(\mathrm{d}, \mathrm{p})$ level of theory ${ }^{43,44}$ using the Gaussian09 program. $^{45}$ Solvent effects were taken into account by using the universal continuum solvation model based on electron density (SMD). ${ }^{46}$ First, a reaction pathway involving a point defect in FG was investigated (Figure S20). Radical point defects (one fluorine atom missing) present in real FG samples have previously been identified as strong electrophiles responsible for the reactivity of FG. ${ }^{47,48}$ Thus, we anticipated that the reaction might proceed via nucleophilic attack of $\mathrm{NH}_{2}{ }^{-}$on a point defect, followed by dissociation of an adjoining $\mathrm{C}-\mathrm{F}$ bond (reaction energy $\left.\Delta E_{\mathrm{R}}=-62.1 \mathrm{kcal} \cdot \mathrm{mol}^{-1}\right)$. The amino groups can either react with radical species leading to byproducts observed experimentally (see Scheme 1) or be transformed to aziridinic arrangements $\left(\Delta E_{\mathrm{R}}=-42.7 \mathrm{kcal} \cdot \mathrm{mol}^{-1}\right.$, Figure S20-III.a $)$, as also proposed for the attack of $\mathrm{NH}_{3}$ on FG. ${ }^{49} \mathrm{C}-\mathrm{F}$ bond dissociation and release of $\mathrm{F}^{-}$and $\mathrm{HF}$ (transformed to $\mathrm{F}^{-}$by reaction with $\mathrm{NH}_{2}^{-}$) were supported by the experimental observation of $\mathrm{NaF}$ based on XRD measurements (Figure $\mathrm{S} 15 \mathrm{a})$. As the aziridinic group is highly reactive, it would be chemically transformed in a reaction mixture containing strong nucleophiles and radicals (see Scheme 1). Therefore, neither amino nor aziridinic functionalities should be expected in NG, in line with the $\mathrm{N}$ 1s XPS data.

Taking into account the high reactivity of the aziridinic group, we considered a reaction mechanism that could potentially lead to the formation of an in-plane nitrogen configuration (Figure S20). However, the reaction step involving the cleavage of lattice $\mathrm{C}-\mathrm{C}$ bonds was found to be prohibited due to a high energy barrier $\left(E_{\mathrm{a}}>100 \mathrm{kcal} \cdot \mathrm{mol}^{-1}\right.$, Figures S21 and S22). Therefore, the direct insertion of nitrogen into an unperturbed FG lattice seems to be highly improbable, and the presence of vacancies in the lattice needs to be considered to explain the feasibility of the $\mathrm{N}$-doping process under mild conditions.

To investigate the types of vacancies that may occur in the starting material, we performed periodic boundary condition (PBC) calculations using spin-polarized DFT in combination with the Perdew, Burke, and Ernzerhof functional with Grimme correction (PBE-D2) $)^{50}$ and projected augmented wave potentials (PAW) representing atomic cores, as 
implemented in the Vienna ab initio simulation package (VASP).$^{51-54}$ For further computational details, see the SI. Several types of vacancies are known to occur in a graphene lattice $^{55}$ and may also exist in FG: point defects (e.g., StoneWales vacancy SW(55-77)), single vacancies (SV), double vacancies (DV), triple vacancies (TV), etc. Since a distribution of spin-carrying sites was found in FG samples, ${ }^{48}$ we also included vacancies with radical centers as well as biradical sites. The distances between radical centers on the edges of vacancies (2.9-7.5 $\AA$ ) corresponded to values estimated experimentally using electron paramagnetic resonance (EPR) (4.8-7.3 $\AA$ in freshly prepared sample, $3.9 \AA$ after treatment with DMF). ${ }^{48}$

On the basis of a comparison of cohesion energies (eq S1 in SI), SW(55-77) and DV(555-777) vacancies were identified as the most stable (Figure S23). However, a combination of these vacancies with a point defect is not probable due to the high $\mathrm{C}-\mathrm{F}$ bond dissociation energy, which is comparable with that of unperturbed FG $\left(\sim 100 \mathrm{kcal} \cdot \mathrm{mol}^{-1}\right)$. Therefore, we studied the nucleophilic attack of $\mathrm{NH}_{2}{ }^{-}$on radical centers of the third and fourth most stable vacancies, namely SV and DV(14) (Figure 4a,b and Figures S24 and S25). The first reaction step, i.e., $\mathrm{NH}_{2}^{-}$nucleophilic attack accompanied by release of a fluorine anion, was more favorable for $\mathrm{DV}(14)$ $\left(\Delta E_{\mathrm{R}}=-65.1 \mathrm{kcal} \cdot \mathrm{mol}^{-1}\right.$, Figure $\left.4 \mathrm{a}\right)$ than for SV $\left(\Delta E_{\mathrm{R}}=3.8\right.$ $\mathrm{kcal} \cdot \mathrm{mol}^{-1}$, Figure $\left.4 \mathrm{~b}\right)$. The reaction then proceeded via dehydrogenation and further defluorination. $\mathrm{N}$ incorporation into SV led to formation of graphitic nitrogen and was energetically the most favorable $\left(\Delta E_{\mathrm{R}}=-255.5 \mathrm{kcal} \cdot \mathrm{mol}^{-1}\right)$. In the case of $\mathrm{DV}(14)$, we considered the formation of both pyridinic and pyrrolic $\mathrm{N}$. While the creation of a six-membered ring with pyridinic $\mathrm{N}$ was found to be feasible $(\Delta E=-72.3$ $\mathrm{kcal} \cdot \mathrm{mol}^{-1}$, Figure 4a), the formation of a five-membered ring with pyrrolic $\mathrm{N}$ was less favorable $\left(\Delta E=-32.6 \mathrm{kcal} \cdot \mathrm{mol}^{-1}\right)$. These findings suggest that the $\mathrm{N}$-doping process predominantly involves the formation of graphitic and pyridinic structures. It should also be noted that nucleophilic attack can lead to the expansion of a vacancy (Figure S34). This process can increase the number of active sites on the lattice and thus significantly affect the amount of incorporated nitrogen atoms.

We also employed GC-MS to verify the suggested reaction mechanism in DMF. GC-MS analysis of supernatants acquired by centrifugation of the reaction mixture revealed that various species were formed during the $\mathrm{N}$-doping process (Tables $\mathrm{S} 1$, S2, Figures S16-S19). The main byproducts included dimethylamine (DMA), dimethylaminoacetonitrile (DMAACN), tetramethylurea (TMU), dimethylurea (DMU), and formyltrimethylurea (FTMU). Hence, the reaction system of FG mixed with $\mathrm{NaNH}_{2}$ in DMF evidently involved many side-reactions. By conducting a thorough theoretical exploration of possible reactions of FG with $\mathrm{NH}_{2}{ }^{-}$and those encompassing DMF, we rationalized the occurrence of all the main byproducts observed experimentally (shown in green frames in Scheme 1). Species in orange frames are important for other reactions in the system; some of them are created without the presence of FG and/or $\mathrm{NaNH}_{2}$ (see more comprehensive Schemes $\mathrm{S} 1-\mathrm{S} 3$ in the SI). It is worth noting that the radical centers of FG enable radical reactions and significantly enrich the number of possible byproducts in comparison with DMF and DMF $+\mathrm{NaNH}_{2}$ systems. The GCMS analysis of a supernatant acquired from the reaction mixture in ACN was also performed (see Table S3). The formation of the main byproducts was rationalized by theoretical calculations (Scheme S4). In comparison to those in the reaction in DMF, the byproducts were less diverse, and their formation was energetically less favorable, confirming that $\mathrm{ACN}$ is the least reactive environment among the used solvents.

\section{CONCLUSIONS}

The synthesis of highly $\mathrm{N}$-doped graphene by the reaction of FG with $\mathrm{NaNH}_{2}$ under mild and sustainable conditions was reported. The highest yet recorded nitrogen content of 18.2 at. $\%$ in graphene at mild conditions was attained in acetonitrile as solvent at $70{ }^{\circ} \mathrm{C}$. The nitrogen atoms were assigned as pyrrolic, pyridinic, and graphitic configurations. The product retained the same nitrogen composition and content up to $400{ }^{\circ} \mathrm{C}$, a finding which might have significant applicability in catalysis at elevated temperatures.

DFT calculations revealed that the nucleophilic attack of $\mathrm{NH}_{2}{ }^{-}$on point defects and vacancies naturally present in the starting material was energetically favorable and could explain the formation of pyrrolic, pyridinic, and graphitic configurations observed experimentally. In addition, the suggested mechanism and rationalization of side-reaction pathways corroborated the experimentally determined byproducts of the reaction. It was concluded that the radical centers of FG may trigger a chain of radical side-reactions and enrich the number of byproducts in the reaction system.

The developed synthesis of highly $\mathrm{N}$-doped graphene under mild conditions in solution by exploiting the susceptibility of FG toward nucleophilic agents appears to be a tunable, costeffective, and environmentally friendly pathway for preparing $\mathrm{N}$-doped graphene materials that could have wide applicability in (electro)catalysis, energy production, and storage.

\section{ASSOCIATED CONTENT}

\section{SI Supporting Information}

The Supporting Information is available free of charge at https://pubs.acs.org/doi/10.1021/acssuschemeng.9b07161.

Materials; synthesis of the nitrogen doped graphene (NG); experimental techniques; characterization of materials (XPS, Raman and FTIR spectra, TGA, $\zeta$ potential, gas adsorption/desorption isotherms, GC-MS, NMR); computational details; energy profiles for selected reactions; classification of vacancies; schemes describing side reactions (PDF)

\section{AUTHOR INFORMATION}

\section{Corresponding Authors}

Aristides Bakandritsos - Regional Centre of Advanced Technologies and Materials, Faculty of Science, Palacky University in Olomouc, 78371 Olomouc, Czech Republic; Email: aristeidis.bakandritsos@upol.cz

Miroslav Medved' - Regional Centre of Advanced Technologies and Materials, Faculty of Science, Palacky University in Olomouc, 78371 Olomouc, Czech Republic;

Email: miroslav.medved@upol.cz

Michal Otyepka - Regional Centre of Advanced Technologies and Materials, Faculty of Science and Department of Physical Chemistry, Faculty of Science, Palacky University in Olomouc, 78371 Olomouc, Czech Republic; (1) orcid.org/0000-00021066-5677; Email: michal.otyepka@upol.cz 


\section{Authors}

Dagmar Zaoralová - Regional Centre of Advanced Technologies and Materials, Faculty of Science and Department of Physical Chemistry, Faculty of Science, Palacky University in Olomouc, 78371 Olomouc, Czech Republic

Vítězslav Hrubý - Regional Centre of Advanced Technologies and Materials, Faculty of Science and Department of Physical Chemistry, Faculty of Science, Palacky University in Olomouc, 78371 Olomouc, Czech Republic

Veronika Sedajová - Regional Centre of Advanced Technologies and Materials, Faculty of Science and Department of Physical Chemistry, Faculty of Science, Palacky University in Olomouc, 78371 Olomouc, Czech Republic

Radim Mach - Regional Centre of Advanced Technologies and Materials, Faculty of Science and Department of Physical Chemistry, Faculty of Science, Palacky University in Olomouc, 78371 Olomouc, Czech Republic

Vojtěch Kupka - Regional Centre of Advanced Technologies and Materials, Faculty of Science and Department of Physical Chemistry, Faculty of Science, Palacky University in Olomouc, 78371 Olomouc, Czech Republic

Juri Ugolotti - Regional Centre of Advanced Technologies and Materials, Faculty of Science, Palacky University in Olomouc, 78371 Olomouc, Czech Republic

Complete contact information is available at:

https://pubs.acs.org/10.1021/acssuschemeng.9b07161

\section{Author Contributions}

$\$$ These authors contributed equally to this work.

Notes

The authors declare no competing financial interest.

\section{ACKNOWLEDGMENTS}

We acknowledge financial support from MEYS (CZ.02.1.01/ 0.0/0.0/16_019/0000754, CZ.1.05/2.1.00/19.0377), the ERC (683024 from the H2020) and the Internal Student Grant Agency of the Palacky University in Olomouc, Czech Republic (IGA_PrF_2019_031). Ondřj Tomanec (HR-TEM), Cecilia Maria Reyes Pérez (SEM), Martin Petr (XPS), Jana Havláková (TGA), Kateřina Stymplová and Dr. Zuzana Chaloupková (Raman), Dr. Claudia Aparicio (XRD), and Dr. Eva Otyepková (GC-MS) are acknowledged for the measurements.

\section{REFERENCES}

(1) Rao, C. N. R.; Gopalakrishnan, K.; Govindaraj, A. Synthesis, properties and applications of graphene doped with boron, nitrogen and other elements. Nano Today 2014, 9 (3), 324-343.

(2) Maiti, U. N.; Lee, W. J.; Lee, J. M.; Oh, Y.; Kim, J. Y.; Kim, J. E.; Shim, J.; Han, T. H.; Kim, S. O. 25th Anniversary Article: Chemically Modified/Doped Carbon Nanotubes \& Graphene for Optimized Nanostructures \& Nanodevices. Adv. Mater. 2014, 26 (1), 40-67.

(3) Wang, H.; Maiyalagan, T.; Wang, X. Review on Recent Progress in Nitrogen-Doped Graphene: Synthesis, Characterization, and Its Potential Applications. ACS Catal. 2012, 2 (5), 781-794.

(4) Vineesh, T. V.; Nazrulla, M. A.; Krishnamoorthy, S.; Narayanan, T. N.; Alwarappan, S. Synergistic effects of dopants on the spin density of catalytic active centres of $\mathrm{N}$-doped fluorinated graphene for oxygen reduction reaction. Appl. Mater. Today 2015, 1 (2), 74-79.

(5) Guo, D.; Shibuya, R.; Akiba, C.; Saji, S.; Kondo, T.; Nakamura, J. Active sites of nitrogen-doped carbon materials for oxygen reduction reaction clarified using model catalysts. Science 2016, 351 (6271), 361-365.
(6) Wei, Q.; Tong, X.; Zhang, G.; Qiao, J.; Gong, Q.; Sun, S. Nitrogen-Doped Carbon Nanotube and Graphene Materials for Oxygen Reduction Reactions. Catalysts 2015, 5 (3), 1574-1602.

(7) Liang, P.; Zhang, C.; Duan, X.; Sun, H.; Liu, S.; Tade, M. O.; Wang, S. N-Doped Graphene from Metal-Organic Frameworks for Catalytic Oxidation of p-Hydroxylbenzoic Acid: N-Functionality and Mechanism. ACS Sustainable Chem. Eng. 2017, 5 (3), 2693-2701.

(8) Błoński, P.; Tuček, J.; Sofer, Z.; Mazánek, V.; Petr, M.; Pumera, M.; Otyepka, M.; Zbořil, R. Doping with Graphitic Nitrogen Triggers Ferromagnetism in Graphene. J. Am. Chem. Soc. 2017, 139 (8), $3171-3180$.

(9) Miao, Q.; Wang, L.; Liu, Z.; Wei, B.; Xu, F.; Fei, W. Magnetic properties of $\mathrm{N}$-doped graphene with high Curie temperature. Sci. Rep. 2016, 6, 21832-21842.

(10) Ito, Y.; Christodoulou, C.; Nardi, M. V.; Koch, N.; Kläui, M.; Sachdev, H.; Müllen, K. Tuning the Magnetic Properties of Carbon by Nitrogen Doping of Its Graphene Domains. J. Am. Chem. Soc. 2015, 137 (24), 7678-7685.

(11) Alegaonkar, A. P.; Kumar, A.; Patil, S. H.; Patil, K. R.; Pardeshi, S. K.; Alegaonkar, P. S. Spin Transport and Magnetic Correlation Parameters for Graphene-like Nanocarbon Sheets Doped with Nitrogen. J. Phys. Chem. C 2013, 117 (51), 27105-27113.

(12) Friedman, A. L.; Cress, C. D.; Schmucker, S. W.; Robinson, J. T.; van 't Erve, O. M. J. Electronic transport and localization in nitrogen-doped graphene devices using hyperthermal ion implantation. Phys. Rev. B: Condens. Matter Mater. Phys. 2016, 93 (16), 161409-161418.

(13) Ito, Y.; Christodoulou, C.; Nardi, M. V.; Koch, N.; Sachdev, H.; Mullen, K. Chemical Vapor Deposition of N-Doped Graphene and Carbon Films: The Role of Precursors and Gas Phase. ACS Nano 2014, 8 (4), 3337-3346.

(14) Scardamaglia, M.; Aleman, B.; Amati, M.; Ewels, C.; Pochet, P.; Reckinger, N.; Colomer, J. F.; Skaltsas, T.; Tagmatarchis, N.; Snyders, R.; Gregoratti, L.; Bittencourt, C. Nitrogen implantation of suspended graphene flakes: Annealing effects and selectivity of $\mathrm{sp}^{2}$ nitrogen species. Carbon 2014, 73, 371-381.

(15) Wang, L.; Sofer, Z.; Luxa, J.; Pumera, M. Nitrogen doped graphene: influence of precursors and conditions of the synthesis. $J$. Mater. Chem. C 2014, 2 (16), 2887-2893.

(16) Sui, Z.-Y.; Wang, C.; Yang, Q.-S.; Shu, K.; Liu, Y.-W.; Han, B.H.; Wallace, G. G. A highly nitrogen-doped porous graphene - an anode material for lithium ion batteries. J. Mater. Chem. A 2015, 3 (35), 18229-18237.

(17) Chang, D. W.; Lee, E. K.; Park, E. Y.; Yu, H.; Choi, H.-J.; Jeon, I.-Y.; Sohn, G.-J.; Shin, D.; Park, N.; Oh, J. H.; Dai, L.; Baek, J.-B. Nitrogen-Doped Graphene Nanoplatelets from Simple Solution EdgeFunctionalization for $\mathrm{n}$-Type Field-Effect Transistors. J. Am. Chem. Soc. 2013, 135 (24), 8981-8988.

(18) Wang, H.; Xie, M.; Thia, L.; Fisher, A.; Wang, X. Strategies on the Design of Nitrogen-Doped Graphene. J. Phys. Chem. Lett. 2014, 5 (1), 119-125.

(19) Song, J.; Yu, Z.; Gordin, M. L.; Wang, D. Advanced Sulfur Cathode Enabled by Highly Crumpled Nitrogen-Doped Graphene Sheets for High-Energy-Density Lithium-Sulfur Batteries. Nano Lett. 2016, 16 (2), 864-870.

(20) Liu, D.; Lei, W.; Portehault, D.; Qin, S.; Chen, Y. High Ncontent holey few-layered graphene electrocatalysts: scalable solventless production. J. Mater. Chem. A 2015, 3 (4), 1682-1687.

(21) Jeon, I. Y.; Choi, H. J.; Ju, M. J.; Choi, I. T.; Lim, K.; Ko, J.; Kim, H. K.; Kim, J. C.; Lee, J.-J.; Shin, D.; Jung, S.-M.; Seo, J.-M.; Kim, M.-J.; Park, N.; Dai, L.; Baek, J.-B. Direct nitrogen fixation at the edges of graphene nanoplatelets as efficient electrocatalysts for energy conversion. Sci. Rep. 2013, 3, 2260-2267.

(22) Karlický, F.; Kumara Ramanatha Datta, K.; Otyepka, M.; Zbořil, R. Halogenated Graphenes: Rapidly Growing Family of Graphene Derivatives. ACS Nano 2013, 7 (8), 6434-6464.

(23) Li, Y.; Wang, X.; Wang, W.; Qin, R.; Lai, W.; Ou, A.; Liu, Y.; Liu, X. Nitrogen-Doping Chemical Behavior of Graphene Materials 
with Assistance of Defluorination. J. Phys. Chem. C 2019, 123 (1), 584-592.

(24) Liu, Y.; Shen, Y.; Sun, L.; Li, J.; Liu, C.; Ren, W.; Li, F.; Gao, L.; Chen, J.; Liu, F.; Sun, Y.; Tang, N.; Cheng, H.-M.; Du, Y. Elemental superdoping of graphene and carbon nanotubes. Nat. Commun. 2016, 7 (1), 10921-10930.

(25) Zoppellaro, G.; Bakandritsos, A.; Tuček, J.; Błoński, P.; Susi, T.; Lazar, P.; Bad'ura, Z.; Steklý, T.; Opletalová, A.; Otyepka, M.; Zbořil, R. Microwave Energy Drives "On-Off-On" Spin-Switch Behavior in Nitrogen-Doped Graphene. Adv. Mater. 2019, 31 (37), 19025871902597.

(26) Chronopoulos, D. D.; Bakandritsos, A.; Pykal, M.; Zbořil, R.; Otyepka, M. Chemistry, properties, and applications of fluorographene. Appl. Mater. Today 2017, 9, 60-70.

(27) National Center for Biotechnology Information. PubChem Database. Hydroxylamine hydrochloride, CID $=443297$, https: $/ /$ pubchem.ncbi.nlm.nih.gov/compound/Hydroxylamine-hdyrochloride (accessed on Nov. 6, 2019).

(28) National Center for Biotechnology Information. PubChem Database. Sodium Amide, CID = 24533, https://pubchem.ncbi.nlm. nih.gov/compound/Sodium-amide (accessed on Nov. 6, 2019).

(29) Long, G.; Meek, M. E. N, N-dimethylformamide: Hazard characterization and exposure-response analysis. J. Environ. Sci. Heal. C 2001, 19 (1), 161-187.

(30) National Center for Biotechnology Information. PubChem Database. $N, N$-Dimethylformamide, CID $=6228$, https: $/ /$ pubchem . ncbi.nlm.nih.gov/compound/N_N-Dimethylformamide (accessed on Nov. 6, 2019).

(31) National Center for Biotechnology Information. PubChem Database. Propylene carbonate, CID $=7924$, https: //pubchem.ncbi. nlm.nih.gov/compound/Propylene-carbonate (accessed on Nov. 6, 2019).

(32) National Center for Biotechnology Information. PubChem Database. Acetonitrile, CID $=6342$, https: $/ /$ pubchem.ncbi.nlm.nih. gov/compound/Acetonitrile (accessed on Nov. 6, 2019).

(33) Mayo, D. W. Course Notes on the Interpretation of Infrared and Raman Spectra (Eds. Mayo, D. W.; Miller, F. A.; Hannah, R. W.), John Wiley \& Sons, Inc.: 2004; pp 101-140.

(34) Senthilnathan, J.; Weng, C.-C.; Liao, J.-D.; Yoshimura, M. Submerged Liquid Plasma for the Synthesis of Unconventional Nitrogen Polymers. Sci. Rep. 2013, 3 (1), 2414-2421.

(35) Bakandritsos, A.; Kadam, R. G.; Kumar, P.; Zoppellaro, G.; Medved', M.; Tucek, J.; Montini, T.; Tomanec, O.; Andryskova, P.; Drahos, B.; Varma, R. S.; Otyepka, M.; Gawande, M. B.; Fornasiero, P.; Zboril, R. Mixed-Valence Single-Atom Catalyst Derived from Functionalized Graphene. Adv. Mater. 2019, 31 (17), 19003231900332.

(36) Lazar, P.; Mach, R.; Otyepka, M. Spectroscopic Fingerprints of Graphitic, Pyrrolic, Pyridinic, and Chemisorbed Nitrogen in N-Doped Graphene. J. Phys. Chem. C 2019, 123 (16), 10695-10702.

(37) Bakandritsos, A.; Pykal, M.; Błoński, P.; Jakubec, P.; Chronopoulos, D. D.; Poláková, K.; Georgakilas, V.; Čépe, K.; Tomanec, O.; Ranc, V.; Bourlinos, A. B.; Zbořil, R.; Otyepka, M. Cyanographene and Graphene Acid: Emerging Derivatives Enabling High-Yield and Selective Functionalization of Graphene. ACS Nano 2017, 11 (3), 2982-2991.

(38) Kumar, A.; Ganguly, A.; Papakonstantinou, P. Thermal stability study of nitrogen functionalities in a graphene network. J. Phys.: Condens. Matter 2012, 24 (23), 235503-235510.

(39) Potsi, G.; Bourlinos, A. B.; Mouselimis, V.; Poláková, K.; Chalmpes, N.; Gournis, D.; Kalytchuk, S.; Tomanec, O.; Błoński, P.; Medved', M.; Lazar, P.; Otyepka, M.; Zbořil, R. Intrinsic photoluminescence of amine-functionalized graphene derivatives for bioimaging applications. Appl. Mater. Today 2019, 17, 112-122.

(40) Luo, G.; Liu, L.; Zhang, J.; Li, G.; Wang, B.; Zhao, J. Hole Defects and Nitrogen Doping in Graphene: Implication for Supercapacitor Applications. ACS Appl. Mater. Interfaces 2013, 5 (21), 11184-11193.
(41) Wang, X.; Sun, G.; Routh, P.; Kim, D.-H.; Huang, W.; Chen, P. Heteroatom-doped graphene materials: syntheses, properties and applications. Chem. Soc. Rev. 2014, 43 (20), 7067-7098.

(42) Tundo, P.; Musolino, M.; Aricò, F. The reactions of dimethyl carbonate and its derivatives. Green Chem. 2018, 20 (1), 28-85.

(43) Chai, J.-D.; Head-Gordon, M. Long-range corrected hybrid density functionals with damped atom-atom dispersion corrections. Phys. Chem. Chem. Phys. 2008, 10 (44), 6615-6620.

(44) Ditchfield, R.; Hehre, W. J.; Pople, J. A. Self-Consistent Molecular-Orbital Methods. IX. An Extended Gaussian-Type Basis for Molecular-Orbital Studies of Organic Molecules. J. Chem. Phys. 1971, 54 (2), 724-728.

(45) Frisch, M. J. et al. Gaussian 09. 2016, Gaussian, Inc., Wallingford CT.

(46) Marenich, A. V.; Cramer, C. J.; Truhlar, D. G. Universal Solvation Model Based on Solute Electron Density and on a Continuum Model of the Solvent Defined by the Bulk Dielectric Constant and Atomic Surface Tensions. J. Phys. Chem. B 2009, 113 (18), 6378-6396.

(47) Matochová, D.; Medved', M.; Bakandritsos, A.; Steklý, T.; Zbořil, R; Otyepka, M. 2D Chemistry: Chemical Control of Graphene Derivatization. J. Phys. Chem. Lett. 2018, 9 (13), 35803585.

(48) Medved', M.; Zoppellaro, G.; Ugolotti, J.; Matochová, D.; Lazar, P.; Pospísil, T.; Bakandritsos, A.; Tuček, J.; Zbořil, R.; Otyepka, M. Reactivity of fluorographene is triggered by point defects: beyond the perfect 2D world. Nanoscale 2018, 10 (10), 4696-4707.

(49) Li, X.-F.; Lian, K.-Y.; Liu, L.; Wu, Y.; Qiu, Q.; Jiang, J.; Deng, M.; Luo, Y. Unraveling the formation mechanism of graphitic nitrogen-doping in thermally treated graphene with ammonia. Sci. Rep. 2016, 6, 23495-23504.

(50) Grimme, S. Semiempirical GGA-type density functional constructed with a long-range dispersion correction. J. Comput. Chem. 2006, 27 (15), 1787-1799.

(51) Kresse, G.; Furthmüller, J. Efficient iterative schemes for ab initio total-energy calculations using a plane-wave basis set. Phys. Rev. B: Condens. Matter Mater. Phys. 1996, 54 (16), 11169-11186.

(52) Kresse, G.; Furthmüller, J. Efficiency of ab-initio total energy calculations for metals and semiconductors using a plane-wave basis set. Comput. Mater. Sci. 1996, 6 (1), 15-50.

(53) Kresse, G.; Joubert, D. From ultrasoft pseudopotentials to the projector augmented-wave method. Phys. Rev. B: Condens. Matter Mater. Phys. 1999, 59 (3), 1758-1775.

(54) Blöchl, P. E. Projector augmented-wave method. Phys. Rev. B: Condens. Matter Mater. Phys. 1994, 50 (24), 17953-17979.

(55) Banhart, F.; Kotakoski, J.; Krasheninnikov, A. V. Structural Defects in Graphene. ACS Nano 2011, 5 (1), 26-41. 